ORIGINAL ARTICLE

\title{
Anthropometry, physical performance, and ultrasound patellar tendon abnormality in elite junior basketball players: a cross-sectional study
}

\author{
J L Cook, Z S Kiss, K M Khan, C R Purdam, K E Webster
}

Br J Sports Med 2004;38:206-209. doi: 10.1136/bjsm.2003.004747

See end of article for authors' affiliations a thors' affilialions

Correspondence to: J L Cook, La Trobe University, Musculoskeletal Research Centre, School of Physiotherapy, Bundoora, Vic. 3083, Australia; j.cook@latrobe.edu.au

Accepted 15 April 2003

\begin{abstract}
Objective: Patellar tendinopathy has been reported to be associated with many intrinsic risk factors. Few have been fully investigated. This cross-sectional study examined the anthropometric and physical performance results of elite junior basketball players with normal or abnormal patellar tendons to see if any measures were associated with changes in tendon morphology.

Methods: Agility, leg strength, endurance, and flexibility were measured in 71 male and 64 female players. A blinded radiologist ultrasonographically examined their patellar tendons and athletes were grouped as having normal or abnormal tendons. One-way ANOVA was used to test for differences in anthropometric and physical performance data for athletes whose tendons were normal or abnormal (unilateral or bilateral tendinopathy) on ultrasound.

Results: Results show that females with abnormalities in their tendons had a significantly better vertical jump $(50.9 \pm 6.8 \mathrm{~cm})$ than those with normal tendons $(46.1 \pm 5.4 \mathrm{~cm})(p=0.02)$. This was not found in males. In males, the mean sit and reach in those with normal tendons $(13.2 \pm 6.7 \mathrm{~cm})$ was greater $(p<0.03)$ than in unilateral tendinopathy $(10.3 \pm 6.2 \mathrm{~cm})$ or in bilateral tendinopathy $(7.8 \pm 8.3 \mathrm{~cm})$. In females, those with normal tendons $(13.3 \pm 4.8 \mathrm{~cm})$ and bilateral tendinopathy $(15.8 \pm 6.2 \mathrm{~cm})$ were distinctly different from those with unilateral tendinopathy $(7.9 \pm 6.6 \mathrm{~cm})$.

Conclusion: Flexibility and vertical jump ability are associated with patellar tendinopathy and the findings warrant consideration when managing young, jumping athletes.
\end{abstract}

$\mathrm{P}$ atellar tendinopathy is a problematic condition in basketball players that can limit or even end a professional sporting career. Treatment options are poorly researched $^{1}$ and outcomes after both conservative and surgical treatments may offer incomplete recovery and difficulties returning to sport. ${ }^{23}$

Patellar tendinopathy is assessed by clinicians with history, examination, and imaging (ultrasound and magnetic resonance imaging). Tendon imaging detects changes in tendon morphology in symptomatic athletes, but has also shown abnormality before symptoms arise. ${ }^{45}$

Intrinsic risk factors such as individual biomechanics are also examined clinically in symptomatic athletes. Many intrinsic risk factors for the development of patellar tendinopathy have been reported in the literature ${ }^{6}$ but few have been investigated thoroughly. ${ }^{7}$ Athletic ability may also be associated with patellar tendinopathy, specifically better athletes may be more likely to have symptoms of patellar tendinopathy. ${ }^{8}$ Given these reported associations, further investigations into patellar tendinopathy and physical performance seem warranted.

Similarly, few specific anthropometric profiles have been reported for patellar tendinopathy, but there appears to be some evidence that individual body factors may be associated with lower limb injury, ${ }^{9}$ specifically high body fat, fitness, and female gender. Also, a recent prospective study has suggested that anterior and posterior thigh flexibility may increase the risk of developing symptoms of jumper's knee. ${ }^{10}$ Thus we sought to further examine the relationship between patellar tendinopathy and anthropometric measures.

To our knowledge, no studies have investigated the relationship between physical and anthropometric measures and patellar tendon morphology on imaging. The aim of this cross-sectional study was to categorise patellar tendon morphology of elite young basketball athletes with ultrasound as normal or abnormal and relate these findings to athletes' anthropometric measurements and physical performance.

\section{METHODS \\ Subjects}

Each year, the most talented 14-18 year old basketball players in Australia participate in a 7 day All-Australian training camp. We attended three consecutive camps to collect clinical, anthropometric, physical performance, and ultrasonographic data in this population. For subjects that attended for more than one camp, the data from the first camp were used.

The study was approved by the Ethics Committee, Griffith University. All subjects, or parents/guardians if under age, provided written informed consent.

\section{Anthropometric measurements}

Trained anthropometrists measured height, weight, arm span, skinfolds (eight sites), and sit and reach using standard protocols in all subjects. The same examiner measured all subjects for each specific test procedure. These tests were chosen as simple and reliable tests ${ }^{11}$ that could be performed efficiently on a large cohort of athletes, as the time constraints of a training camp would not allow time consuming testing. Similarly these tests were required to have relevance for coaching staff attempting to interpret athlete performance.

\section{Physical performance testing}

Exercise physiologists conducted the physical performance tests. The same examiner measured all subjects for each specific test procedure. Tests were specifically selected to 
assess speed, agility, endurance, and leg strength. The reliability and validity of these physical tests have previously been reported. ${ }^{12} 13$

- Speed was measured with a $10 \mathrm{~m}$ sprint using timing gates (Swift Technologies, NSW, Australia).

- Agility was measured with the athlete lying prone facing the court at baseline for the start. At the sound of a starting gun, each subject stood and ran to the free throw line and returned to touch the baseline. The time taken to complete the agility run was measured with timing gates.

- Functional leg strength was measured by vertical jump, performed from a stride jump start position, with the favoured jumping leg under a vertical measuring device (Swift Technologies, NSW, Australia) and the other leg placed wherever it was comfortable. The subject jumped from, and landed on, both legs. The distance jumped was recorded in centimetres.

- Endurance was measured with an exercise test to assess maximal aerobic power-the 20 -m shuttle test. This test has a start speed of $8.5 \mathrm{~km} / \mathrm{h}$ and increases at $0.5 \mathrm{~km} / \mathrm{h}$ every minute. The speed at which the subject can no longer keep pace is taken as the level completed. A speed of $8.5 \mathrm{~km} / \mathrm{h}$ is "level 0 " and a speed of $18 \mathrm{~km} / \mathrm{h}$ is "level $20^{\prime \prime}{ }^{14}$

Subjects completed two trials of each test, except for the endurance test, and the best result was recorded.

\section{Correlation between physical tests}

There was a significant correlation between vertical jump and $10 \mathrm{~m}$ sprint in males $(\mathrm{r}=0.376, \mathrm{p}=0.002)$ and females $(r=0.475, p=0.000)$. This indicated common elements between the two tests and overlap between what the tests were measuring. We still considered it important to examine and report on both these physical performance tests, as they reflect important components of basketball performance. There were no other significant correlations between any of the other tests.

\section{Ultrasonographic assessment}

Ultrasound examination was chosen to examine the patellar tendons in this study because of the ease and cost of examination, and the absence of ionising radiation. Ultrasound has been shown to be a reliable and valid tendon examination method and the musculoskeletal radiologist in this study (ZSK) has previously been shown to have excellent agreement in detecting tendon abnormality in a similar group of subjects.

The radiologist performed ultrasonography using a highresolution linear array 10 or $12 \mathrm{MHz}$ ultrasound transducer (Acoustic Imaging Dornier, Phoenix, USA). An ultrasonographic abnormality was defined as abnormality in the fibre structure of the tendon evident in both the longitudinal and the transverse scans. Most commonly this is seen as a hypoechoic region or fusiform swelling. All tendons in this study had clear hypoechoic areas with widened anteroposterior diameter.

The radiologist was blinded to players' symptomatic and performance status at all times. All subjects were scanned during the camp, within $24 \mathrm{~h}$ of the anthropometric and physical testing procedures. Subjects were categorised as "normal" (group 1) or "abnormal" (group 2) depending on ultrasonographic appearances of their patellar tendons. Subjects with abnormal tendons were further divided into those with either unilateral (group 2a) or bilateral (group 2b) abnormality.

\section{Clinical assessment}

All subjects completed a questionnaire regarding current symptoms of patellar tendon pain (yes/no). Subjects with current knee pain illustrated its site on a knee chart to help differentiate tendon pain from patellofemoral pain. The presence of symptoms of extensor mechanism pain, although recorded, was not included in the analysis of results in this study for two reasons. First, all athletes were training and playing fully, and symptoms did not appear to affect the physical test results or the playing capacity of the athletes. Second, as many studies have previously reported on symptomatic patellar tendinopathy, this study sought to focus on the morphological changes in the tendon and associated factors.

\section{Group allocation}

Male and female data were analysed separately because of the accepted anthropometric and physical differences between genders. As recent studies have reported that the anthropometric and physical testing results are different in unilateral and bilateral patellar tendinopathy, ${ }^{15}$ we analysed those with tendinopathy in one or both knees as different groups.

\section{Data analysis}

Data were analysed with SPPS (Version 10). One-way ANOVA was then used to assess for differences between the three subject groups (ultrasound (US) normal (group 1), unilateral tendinopathy (group 2a), and bilateral tendinopathy (group 2b)) for the clinical, anthropometric, and physical performance data. Planned comparisons were then made using contrast coefficients between groups 1 and $2 \mathrm{a}$, groups 1 and $2 \mathrm{~b}$, and groups $2 \mathrm{a}$ and $2 \mathrm{~b}$.

\section{RESULTS}

A total of 71 male and 64 female players completed most assessments. All subjects had an ultrasound examination, though up to five different players missed tests for a variety of reasons not including injury or inability to perform.

Ultrasound revealed that $54 \%$ of male tendons were normal (group 1), as were $75 \%$ of female tendons. In players who had abnormal tendon morphology, there were almost exactly equal numbers with unilateral and bilateral abnormalities (table 1).

\section{Anthropometric measures}

There was no difference in height, weight, skinfolds, or arm span/height between players grouped by tendon morphology in either gender. The ultrasound tendon status together with anthropometric data of these subjects is shown in tables 1 and 2 .

In both males and females, one way ANOVA revealed significant differences in sit and reach scores between athletes in the three tendon morphology groups (female: $\mathrm{F}(2,61)=4.93, \mathrm{p}=0.01$; male: $\mathrm{F}(2,65)=3.54, \mathrm{p}=0.035)$. In females, planned comparisons revealed significantly reduced sit and reach scores in those with unilateral tendinopathy compared to both those with normal tendons $(p=0.01)$ and bilateral tendinopathy $(p=0.004)$. In males, planned comparisons showed a significant difference between those with normal tendons and bilateral tendinopathy $(p=0.03)$, with the bilateral abnormality group recording smaller sit and reach scores (table 2 ).

\section{Physical performance tests}

Physical performance data of subjects with normal tendons were compared to those with unilateral and bilateral tendon abnormality. Agility, endurance, and speed tests revealed no 
Table 1 Female anthropometric measures by tendon morphology group

\begin{tabular}{llccc}
\hline & $\begin{array}{l}\text { Number in } \\
\text { each test }\end{array}$ & $\begin{array}{l}\text { Normal US } \\
\text { (group 1) }\end{array}$ & $\begin{array}{l}\text { Unilateral changes } \\
\text { (group 2a) }\end{array}$ & $\begin{array}{l}\text { Bilateral changes } \\
\text { (group 2b) }\end{array}$ \\
\hline Total number & 64 & 48 & 8 & 8 \\
Height $(\mathrm{cm})$ & 64 & $177.1(9.2)$ & $180.9(5.0)$ & $174.8(7.6)$ \\
Weight $(\mathrm{kg})$ & 64 & $67.9(9.1)$ & $69.5(7.4)$ & $67.1(10.0)$ \\
Sit and reach $(\mathrm{cm})$ & 64 & $13.3(4.8) \dagger$ & $7.9(6.6)^{*}+$ & $15.8(6.2)^{*}$ \\
Skinfolds $(\mathrm{mm})$ & 63 & $95.6(20.6)$ & $85.1(23.4)$ & $89.0(26.8)$ \\
Arm span/height $(\mathrm{cm})$ & 64 & $1.01(0.03)$ & $1.01(0.03)$ & $1.00(0.03)$ \\
\hline \multirow{7}{*}{ *Tubjects with unilateral tendinopathy were significantly less flexible than those with normal tendons or bilateral } \\
tendinopathy $(\mathrm{p}<0.05)$. Data are reported as mean (SD).
\end{tabular}

Table 2 Male anthropometric measures by tendon morphology group

\begin{tabular}{llccc}
\hline & $\begin{array}{l}\text { Number in } \\
\text { each test }\end{array}$ & $\begin{array}{l}\text { Normal US } \\
\text { (group 1) }\end{array}$ & $\begin{array}{l}\text { Unilateral changes } \\
\text { (group 2a) }\end{array}$ & $\begin{array}{c}\text { Bilateral changes } \\
\text { (group 2b) }\end{array}$ \\
\hline Number & 71 & 38 & 17 & 16 \\
Height $(\mathrm{cm})$ & 71 & $191.4(9.2)$ & $193.3(7.0)$ & $195.1(5.0)$ \\
Weight $(\mathrm{kg})$ & 71 & $81.4(9.5)$ & $83.8(7.5)$ & $85.6(8.9)$ \\
Sit and reach $(\mathrm{cm})$ & 68 & $13.2(6.7) *$ & $10.3(6.2)$ & $7.8(8.3)^{*}$ \\
Skinfolds $(\mathrm{mm})$ & 71 & $59.2(14.7)$ & $66.9(18.6)$ & $66.0(21.2)$ \\
Arm span/height (cm) & 70 & $1.03(0.02)$ & $1.03(0.02)$ & $1.03(0.02)$ \\
\hline
\end{tabular}

statistically significant differences between groups in either gender (tables 3 and 4).

Physical performance data indicated differences in vertical jump between groups in female subjects $(F(2,61)=4.02$, $\mathrm{p}=0.023)$, but not in males $(\mathrm{F}(2,63)=0.596, \mathrm{p}=0.5)$. In females, planned comparisons revealed that female players with abnormal tendons (unilateral and bilateral tendinopathy) had a greater vertical jump than those with normal tendons $(\mathrm{p}<0.039)$. There was no significant difference in jump height between those with unilateral and bilateral tendinopathy.

Following this finding in females, we decided to analyse the effect of symptoms on vertical jump height in those males with tendon changes in case pain was reducing jump height. Of the players with abnormal tendons 17 players were asymptomatic and 14 players reported localised tendon pain. of this group, there was no significant difference in jump height between those players with, and those without, pain $(\mathrm{t}=0.148, \mathrm{p}=0.883)$.

\section{DISCUSSION}

Examining anthropometric and physical performance factors and their association with the presence of US changes in the patellar tendon has clinical relevance, as factors that are pertinent to the development of tendon pathology are likely to contribute to the development of symptoms. Asymptomatic patellar tendinopathy has been shown to progress to symptomatic tendinopathy in these athletes, ${ }^{4}$ so these results may have clinical importance when managing symptomatic patellar tendinopathy.

In this group of athletes, patellar tendon abnormality was not associated with specific anthropometric characteristics. Some previous studies have reported a relationship between injury and anthropometric measurements, but nearly all

Table 3 Physical performance tests and tendon morphology group in females

\begin{tabular}{llllc}
\hline & $\begin{array}{l}\text { Number in } \\
\text { each test }\end{array}$ & $\begin{array}{l}\text { Normal US } \\
\text { (group 1) }\end{array}$ & $\begin{array}{l}\text { Unilateral changes } \\
\text { (group 2a) }\end{array}$ & $\begin{array}{l}\text { Bilateral changes } \\
\text { (group 2b) }\end{array}$ \\
\hline Number & 64 & 48 & 8 & 8 \\
Agility (s) & 62 & $5.48(0.60)$ & $5.37(0.71)$ & $5.31(0.73)$ \\
Endurance (level) & 60 & $9.8(1.4)$ & $9.3(1.5)$ & $10.1(1.4)$ \\
Vertical jump (cm) & 64 & $46.1(5.4)^{*} \dagger$ & $50.9(4.7)^{*}$ & $51.0(9.0) \dagger$ \\
10 m sprint (s) & 63 & $1.94(0.08)$ & $1.9(0.07)$ & $1.9(0.08)$ \\
\hline
\end{tabular}

${ }^{*}+$ Subjects with unilateral and bilateral tendinopathy had a significantly greater vertical jump than subjects with normal tendons $(p<0.05)$. Data are reported as mean (SD).

Table 4 Physical performance tests and tendon morphology group in males

\begin{tabular}{lllll}
\hline & $\begin{array}{l}\text { Number in } \\
\text { each test }\end{array}$ & $\begin{array}{l}\text { Normal US } \\
\text { (group 1) }\end{array}$ & $\begin{array}{l}\text { Unilateral changes } \\
\text { (group 2a) }\end{array}$ & $\begin{array}{l}\text { Bilateral changes } \\
\text { (group 2b) }\end{array}$ \\
\hline Number & 71 & 38 & 17 & 16 \\
Agility (s) & 68 & $5.14(0.52)$ & $5.17(0.64)$ & $5.0(0.5)$ \\
Endurance (level) & 66 & $11.6(1.4)$ & $11.9(1.5)$ & $11.6(1.1)$ \\
Vertical jump (cm) & 69 & $62.0(6.7)$ & $63.4(6.0)$ & $64.4(6.3)$ \\
$10 \mathrm{~m}$ sprint (s) & 68 & $1.76(0.07)$ & $1.78(0.06)$ & $1.76(0.08)$ \\
\hline \multicolumn{7}{l}{ Data are reported as mean (SD). } \\
\end{tabular}




\section{Take home message}

It would appear reasonable for clinicians to (i) assess posterior thigh tightness in pre-season screening of jumping athletes, and (ii) consider treating it if it is present in an athlete with symptomatic jumper's knee. Furthermore, our data suggest the clinician should have a high index of suspicion for underlying morphological abnormalities in female athletes who are good at jumping, even though they might be only be aged between 14 and 18 years.

these studied acute injuries or symptomatic subjects. As our study used US status to define patellar tendinopathy, and not symptoms or injury, different findings are possible.

These current data support the importance of flexibility in preventing morphological tendon change as well as symptoms, as suggested by Witvrouw et al. ${ }^{10}$ In males, it appears flexibility decreases the risk of abnormal tendon morphology. In females, decreased flexibility appears to increase the risk of developing unilateral tendon changes. The reasons for the difference in the sit and reach scores for unilateral and bilateral tendinopathy can only be speculated, however this study provides further support to a small body of evidence that tendinopathy in one or both knees may have a different aetiology. ${ }^{15} 16$ Further research is needed to confirm this complex relationship.

Studies in male athletes have indicated that better jumping ability may predispose to patellar tendinopathy. Lian et $a l^{8}$ showed that male players with symptomatic jumper's knee were able to jump higher than asymptomatic athletes (24 subjects). The current study (71 subjects) showed jump height was similar in males with normal and abnormal tendons, and differences in classifying abnormality (symptoms $v$ morphology) and age of subjects between the studies may explain the difference.

The significant relationship between jumping ability and US tendon changes in female athletes and not male athletes was unexpected. Further research is required to explain the sex difference in our findings, as no other data on jump height in females appear to exist. Similarly, although this study shows an association between posterior thigh flexibility and jump height and changes in tendon morphology, this study has not demonstrated whether tendon changes are a consequence of specific flexibility and jumping ability or if the tendon changes occur first. Similarly, as this study examined a homogeneous (age, level of symptoms, and ability) group of athletes, the findings may not be attributable to all subjects with patellar tendinopathy. Further research is required.

\section{CONCLUSION}

This study suggests that posterior thigh flexibility is associated with morphological patellar tendinopathy. Similarly, female players with high vertical jumps appear to be at increased risk of abnormal tendon morphology. Strict interpretation of these results limits the conclusions we can draw from them for management of clinical patellar tendinopathy.

\section{Authors' affiliations}

J L Cook, K E Webster, Musculoskeletal Research Centre, La Trobe University, Bundoora, Vic. 3083, Australia

Z S Kiss, Medical Imaging Australia, East Melbourne Radiology,

Melbourne, Australia

K M Khan, Departments of Medicine, Orthopaedics and Family Practice, Faculty of Medicine, University of British Columbia, Vancouver, Canada C R Purdam, Sports Science, Sports Medicine, Australian Institute of Sport, PO Box 176, Belconnen, ACT, Australia

\section{REFERENCES}

1 Almekinders L, Temple J. Etiology, diagnosis, and treatment of tendonitis: an analysis of the literature. Med Sci Sport Exerc 1998;30(8):1183-90.

2 Coleman BD, Khan KM, Kiss ZS, et al. Outcomes of open and arthroscopic patellar tenotomy for chronic patellar tendinopathy: a retrospective study. Am J Sports Med 2000;28(2):1-8.

3 Gross MT. Chronic tendonitis: pathomechanics of injury, factors affecting the healing response, and treatment. J Orthop Sports Phys Ther 1992; 16(6):248-61.

4 Cook J, Kiss Z, Khan K, et al. Prospective imaging study of asymptomatic patellar tendinopathy in elite junior basketball players. J Ultrasound Med 2000;19:473-9.

5 Khan KM, Cook JL, Kiss ZS, et al. Patellar tendon ultrasonography and jumper's knee in elite female basketball players: a longitudinal study. Clin J Sports Med 1997;7:199-206.

6 Kannus P. Etiology and pathophysiology of chronic tendon disorders in sport. Scand J Med Sci Sports 1997; 7:78-85.

7 Kujala U, Friberg O, Aalto T, et al. Lower limb asymmetry and patellofemoral joint incongruence in the etiology of knee exertion injuries in athletes. Int J Sports Med 1987; 8:214-20.

8 Lian O, Engebretsen L, Ovrebo RV, et al. Characteristics of the leg extensors in male volleyball players with jumper's knee. Am J Sports Med 1996;24(3):380-5.

9 Neely FG. Intrinsic risk factors for exercise-related lower limb injuries. Sports Med 1998;26(4):253-63.

10 Witvrouw E, Bellemans J, Lysens R, et al. Intrinsic risk factors for the development of patellar tendinitis in an athletic population. A two-year prospective study. Am J Sports Med 2001;29(2):190-5.

11 Hui SS, Yuen PY. Validity of the modified back-saver sit-and-reach test: a comparison with other protocols. Med Sci Sports Exerc 2000;32(9):1655-9.

12 Powers S, Howley E. Exercise Physiology. Theory and Application to Fitness and Performance. Dubuque, IA: Wm C Brown, 1990.

13 Astrand P, Rodahl K. Textbook of Work Physiology. Physiological Bases of Exercise. 3rd ed. Singapore: McGraw-Hill, 1986.

14 Noonan V, Dean E. Submaximal exercise testing: clinical application and interpretation. Phys Ther 2000;80(8):782-807.

15 Gaida JE, Cook JL, Bass SL, Austen S, Kiss ZS. Are unilateral and bilateral patellar tendinopathy distinguished by differences in anthropometry, body composition or muscle strength in elite female basketball players? Br J Sports Med 2004 (in press).

16 Cook JL, Khan KM, Harcourt PR, et al. Patellar tendon ultrasonography in asymptomatic active athletes reveals hypoechoic regions: a study of 320 tendons. Clin J Sports Med 1998;8:73-7. 